\title{
THE EFFECT(S) OF METHANOLIC LEAF EXTRACT OF BAOBAB ON THE HISTOLOGY OF WISTAR RATS KIDNEYS
}

\author{
Eghoi A.M, Paul, C.W *.
}

Department of Anatomy, Faculty of Basic Medical Sciences, University of Port Harcourt, Rivers State. Nigeria.

\section{ABSTRACT}

Introduction: The study investigated the effect(s) of methanolic leaf extract of Baobab (MLEB) on the histology of the albino wistar rats' kidney.

Materials and Method: Thirty-five (35) albino wistar rats were randomly divided into experimental groups (A-C) of ten rats each and a control group (D) of five rats. Their body weights were measured on a weekly basis throughout the period of the experiment. In addition to standard animal feed and water given to all the groups, experimental groups (A, B and C) were orally administered $40 \mathrm{mg} / \mathrm{kg}, 80 \mathrm{mg} / \mathrm{kg}$ and $200 \mathrm{mg} / \mathrm{kg}$ per body weight of MLEB respectively daily for three weeks. During the next four weeks the remaining rats were maintained on standard animal feed and water only, to allow for a wash-out period. The harvest time for Experimental groups were $8^{\text {th }}, 15^{\text {th }}, 22^{\text {nd }}$ and $50^{\text {th }}$ days, while that of control group was $8^{\text {th }}$ and $50^{\text {th }}$ days. Two rats from each group were harvested, their kidneys and blood samples were used for histologic and biochemical studies respectively. Data was analyzed using One-way ANOVA and SPSS version 2.0. Ethical approval was obtained and the international guidelines for animal studies were obeyed.

Results: it was observed that the body weights of experimental groups were not significantly affected $(p<0.05)$ by the MLEB when compared to control group. Significant histo-pathological changes in the kidney were noticed at the various doses of the MLEB. However, only tissues that received $40 \mathrm{mg} / \mathrm{kg}$ of the MLEB recovered at the end of wash-out period.

Discussion: The nephrotoxic effect of the MLEB could be attributed to the presence of alkaloids and tannins.

Conclusion: It was concluded that the toxic effect of the MLEB on the kidney was dose-and time-dependent and was only reversible at a low dose. Thus, regular consumption of large quantities of Baobab leaves for prolonged period should be discouraged as it has been shown to possess deleterious effects on the kidney.

KEY WORDS: Baobab, Distortion, Glomerulus, Obliteration, Reno-toxic, Reversal.

Address for Correspondence: Dr. Paul, C.W, Department of Anatomy, Faculty of Basic Medical Sciences, University of Port Harcourt, Rivers State. Nigeria.

E-Mail: chikwuogwo.paul@uniport.edu.ng

\section{Access this Article online}

\section{Quick Response code}

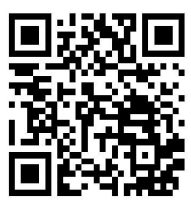

DOI: $10.16965 /$ ijar.2017.449

Web site: International Journal of Anatomy and Research ISSN 2321-4287

www.ijmhr.org/ijar.htm

Received: 16 Sep 2017

Peer Review: 18 Sep 2017

Revised: None
Accepted: 20 Oct 2017

Published (O): 01 Dec 2017

Published (P): 01 Dec 2017

\section{INTRODUCTION}

Baobab (Adansonia digitata L.) possesses unique nutritional properties which have been of immense benefit to man. It is a massive deciduous tree that is indigenous to African savannas and belongs to the family Bombacaceae and genus Adansonia[1].
Baobab is the largest succulent plant in the world with a diameter of 10-12m and a height of $23 \mathrm{~m}$ or more [2,3]. The name Adansonia was given to commemorate the French Surgeon Michael Adanson (1726-1806) while the species digitata refers to the shapes of the leaves.[4] 
Baobab leaves serve as a staple food and a significant source of protein and minerals for many African populations [5,6]. In Zimbabwe, the fresh leaves are cooked as vegetables however in the Northern part of Nigeria its dried leaves are used in making sauces and porridges. The leaves have medicinal value; they are used to treat inflammation, diarrhea, fever, kidney and bladder diseases and blood clearing $[7,8]$. The leaf decoction is used as a treatment for dysentery, diseases of the urinary tract, insect bites, internal pains, otitis and ophthalmia and as a diaphoretic $[2,6]$. The leaves are also used to treat fever, fatigue, malaria, toothache and gingivitis and serve as a febrifuge and immunostimulant $[9,10,5,11,12]$.

The kidneys are bean shaped structures which are reddish brown in life and function to excrete the end products of metabolism and excess water from the blood. The Kidney also have endocrine functions producing and releasing erythropoietin, renin, 1,25-hydroxycholecalciferol, and perhaps modifies the action of the parathyroid hormone, and various other soluble factors with metabolic actions. [13] Both of these actions are essential to the control of concentrations of various substances in the body fluids, e.g. maintaining electrolyte and water balance approximately constant in the tissue fluids.

Baobab leaf and renotoxicity: The present study was undertaken to determine the possible effect(s) of oral administration of methanolic leaf extract of Baobab on the body weight and histology of the kidney.

\section{MATERIALS AND METHODS}

Collection of Plant and Identification: The leaves of baobab was collected from Wondam in Mikang Local Government Area of Plateau State in the month of February and identified at the Department of Plant Science and Biotechnology of the University of Port-Harcourt, Rivers State, Nigeria.

Extraction of plant leaves: The plant leaves were washed with water, cut into smaller pieces and air-dried. The dried leaves were pulverized with an electric blender to a powdered form. From the powdered plant sample, methanolic extracts of the plant leaves was prepared using
Rotary Evaporatory Method.

Procurement and housing of experimental

Animals: Thirty five (35) adult albino wistar rats weighing between 152 and $250 \mathrm{~g}$ were purchased from the animal house of Faculty of Basic Medical Sciences, University of Port Harcourt and housed in wire-netted wooden cages with wooden shavings as their beddings, under standard conditions. They were fed with growers mash (Growers palletized feed) and water ad-libidum for a period of two weeks prior to the study to allow for acclimatization. The weights of the animals were measured at procurement and during the period of acclimatization using an electronic analytical and precision balance.

Experimental design: The study was done for different durations of one week, two weeks, three weeks and a reversal period of four weeks. The weights of the rats were measured at commencement of the experiments and once a week throughout the duration of the experiment, using an electronic analytical and precision balance. The rats were randomly divided into experimental groups (A-C) of ten rats per group and a control group (D) of five rats.

All the groups were fed with a daily standard animal feed and water, while the experimental groups (A-C) were given Methanolic Leaf Extract of Baobab (MLEB) in addition. The experimental groups $(A, B$ and $C)$ were orally administered with $40 \mathrm{mg} / \mathrm{kg}, 80 \mathrm{mg} / \mathrm{kg}$ and $200 \mathrm{mg} / \mathrm{kg}$ body weight of methanolic leaf extract of Baobab once daily respectively for three weeks. On the $8^{\text {th }}$, $15^{\text {th }}, 22^{\text {nd }}$ and $50^{\text {th }}$ days, two animals each from experimental groups (A-C) were anesthetized with chloroform and sacrificed. On $8^{\text {th }}$ and $50^{\text {th }}$ days two animals each from the control group (D) were anesthetized with chloroform and sacrificed. The kidneys were promptly excised and stored in $10 \%$ formalin while blood samples were obtained using a sterile syringe $(5 \mathrm{~mL})$ by cardiac puncture and carefully discharged into lithium heparin bottles.

The blood samples were taken to a medical diagnostic laboratory for creatinine and urea assay. Histological studies on the kidneys were done $[14,15]$.

The sections were stained with Hematoxylin and 
Eosin (H\&E) then viewed under light microscopy. Permanent photomicrograph of each slide was recorded with a Kodak digital camera for subsequent histological analysis. Permission was granted by Research Ethics Committee, College of Graduate Studies, University of Port Harcourt, to carry out this study.

All data were expressed as Mean \pm SEM and statistically analysed using One-way Analysis of Variance (ANOVA) followed by Tukey's posthoc test using statistical package for social sciences version 20 (SPSS 20.0). Values were considered significant at $\mathrm{p}<0.05$.

\section{RESULTS}

Weight of rats: The effect of graded doses of methanolic extract of Baobab on body weights of male albino wistar rats at the end of the first, second, and third weeks and also at the end of the reversal period is presented in table 1 . There was no significant difference in the mean body weights of the experimental groups compared to control (fig. 1). The initial weights of the animals after purchase (control and experimental groups A-C) were 230.13 \pm 15.96 , $198.50 \pm 15.64,189.25 \pm 11.06$ and $182.88 \pm 7.39$ respectively. Although their mean weights differ, the difference was not significant $(p>0.05)$. The increase in mean body weight after acclimatization showed a non-significant difference $(p>0.05)$ between experimental groups (A-C) and control group (D). At the end of the first week of administration of the extract, the increase in mean body weight between experimental groups $(A-C)$ and control group (D) also showed no-significant difference ( $p>0.05$ ). At the end of the second week of administration, experimental groups $(A-C)$ showed

An insignificant increase in mean body weight compared to control group. Similar trend of insignificant increase in mean body weight of experimental animals compared with control was recorded at the end of week three and reversal period.

Table 1: Effects of methanolic leaf extract of Baobab on the weights of male albino wistar rats.

\begin{tabular}{|c|c|c|c|c|}
\hline Time in weeks & $\begin{array}{c}\text { Weight of Control } \\
\text { (g) }\end{array}$ & $\begin{array}{c}\text { Weight of Group } \\
\text { A (g) }\end{array}$ & $\begin{array}{c}\text { Weight of Group } \\
\text { B (g) }\end{array}$ & $\begin{array}{c}\text { Weight of Group } \\
\text { C (g) }\end{array}$ \\
\hline Initial week & $230.13 \pm 15.96$ & $198.50 \pm 15.64$ & $189.25 \pm 11.06$ & $182.88 \pm 7.39$ \\
\hline Acclimatization week & $230.75 \pm 15.98$ & $198.75 \pm 16.10$ & $188.63 \pm 10.28$ & $182.13 \pm 7.06$ \\
\hline Week 1 & $240.38 \pm 16.99$ & $212.00 \pm 17.77$ & $195.75 \pm 12.28$ & $189.75 \pm 8.88$ \\
\hline Week 2 & $251.33 \pm 22.93$ & $218.67 \pm 25.18$ & $197.17 \pm 18.29$ & $197.17 \pm 15.33$ \\
\hline Week 3 & $300.25 \pm 5.68$ & $225.25 \pm 37.60$ & $197.50 \pm 26.53$ & $199.00 \pm 18.88$ \\
\hline Week 7 & $322.50 \pm 2.50$ & $241.50 \pm 63.50$ & $249.00 \pm 71.00$ & $244.00 \pm 52.00$ \\
\hline
\end{tabular}

Values are given as mean \pm SEM for 10 rats in each group; experimental groups are compared with control. Values are statistically not significant.

Fig. 1: Bar chart showing mean body weights of experimental and control groups of albino wistar rats during the period of the experiment.

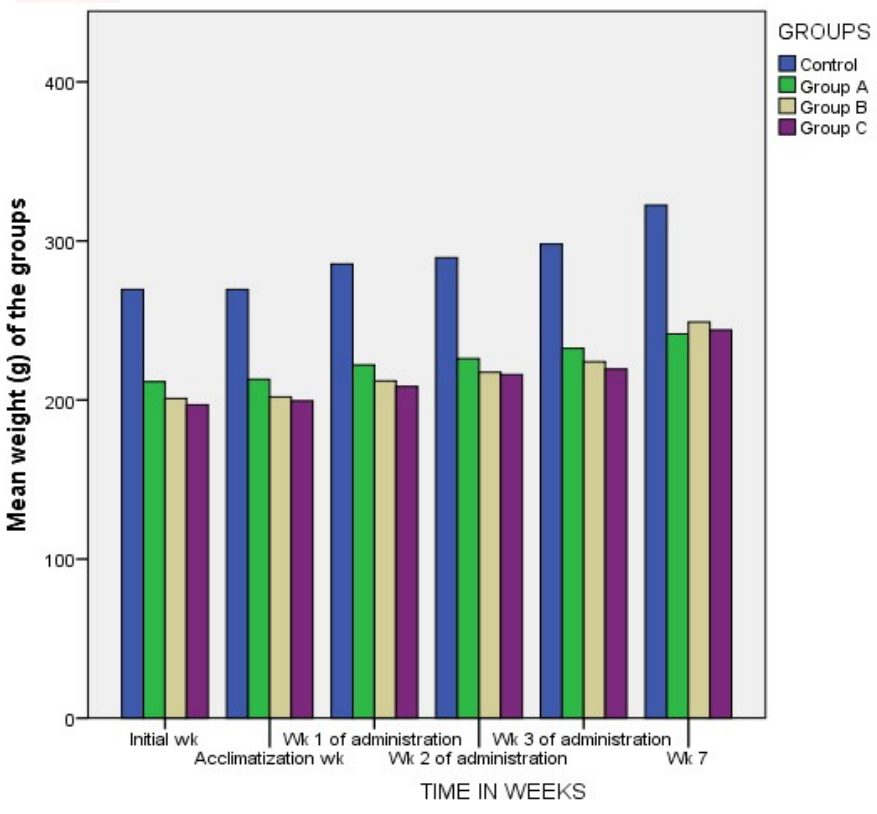


Eghoi A.M, Paul, C.W. THE EFFECT(S) OF METHANOLIC LEAF EXTRACT OF BAOBAB ON THE HISTOLOGY OF WISTAR RATS KIDNEYS.

Histological evaluation of the kidney: The histological profile of sections of all kidneys in the control group (figs. 2-5) appeared normal. Histological assessment of kidneys of animals in group $A(40 \mathrm{mg} / \mathrm{kg})$ showed the presence of partitioned tuft, shrunken glomerular tuft and obliterated tubules at the end of the first, second and third weeks of administration respectively. After a four week wash-out (reversal) period, the histo-pathological distortion reverted to normal._Histology of kidneys from groups B $(80 \mathrm{mg} / \mathrm{kg})$ and C $(200 \mathrm{mg} / \mathrm{kg})$ animals showed evidence of progressive obliteration of glomerular capsular spaces between first and third weeks of extract administration (figs. 4.1, 4.2 and 4.3). At the end of the wash-out period; the histo-pathological distortion in group $B$ $(80 \mathrm{mg} / \mathrm{kg})$ reverted to normal study whereas that in group C $(200 \mathrm{mg} / \mathrm{kg})$ did not show normal histo-architecture (fig. 5).

\section{HISTOLOGY OF THE KIDNEY}

Fig. 2: Micrographs of Albino wistar rats' kidneys at the end of week one. (Mag. X 400; H\&E stain).
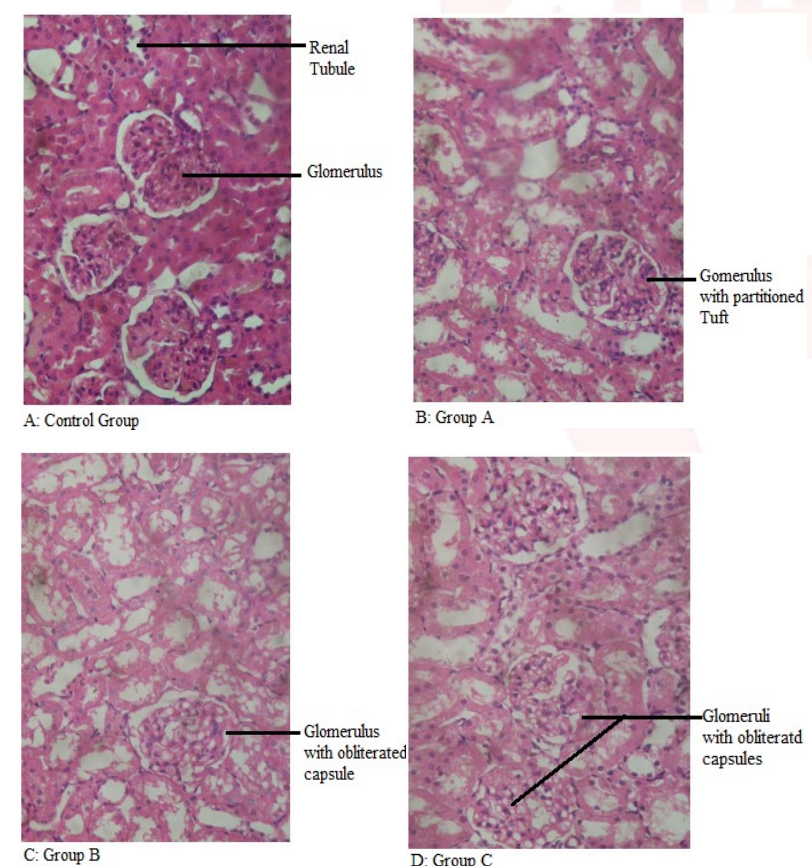

Fig. 3: Micrographs of Albino wistar rats' kidneys at the end of week two. (Mag. X 400; H\&E stain).

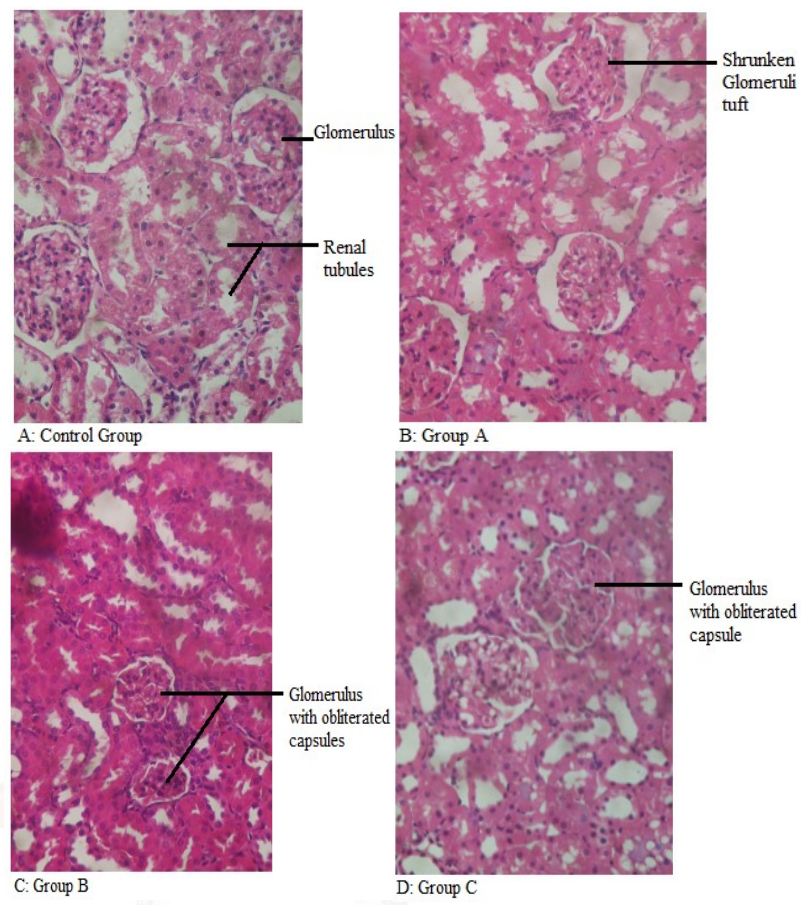

Fig. 4: Micrographs of Albino wistar rats' kidneys at the end of week three. (Mag. X 400; H\&E stain).

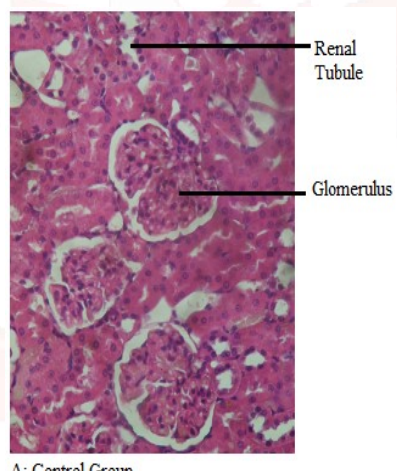

A: Control Group
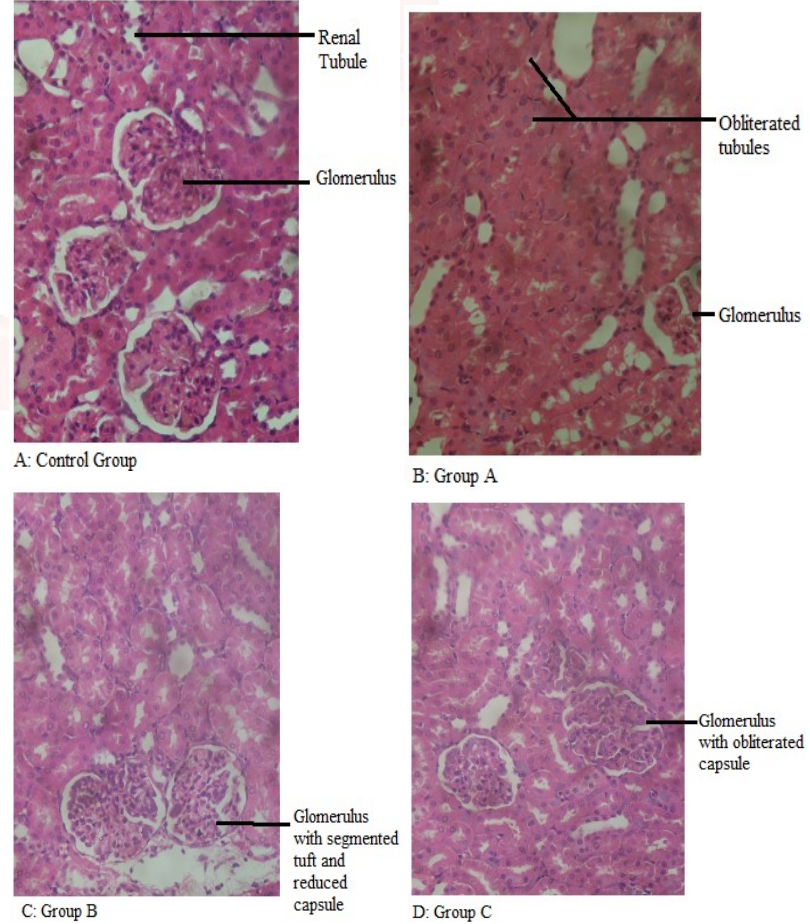

Fig. 5: Micrographs of Albino wistar rats' kidneys at the end of wash-out period. (Mag. X 400; H\&E stain).

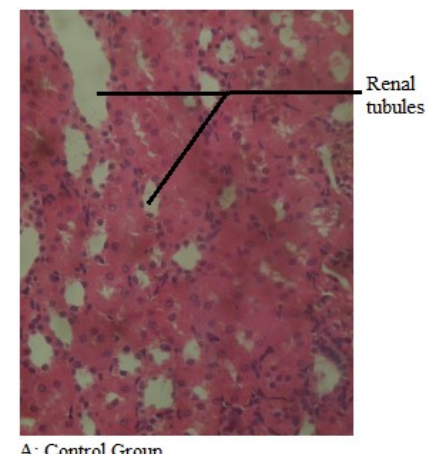

A: Control Group

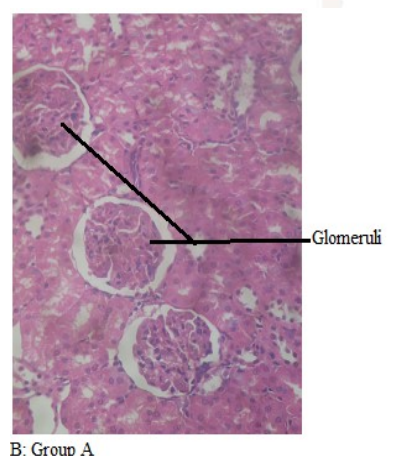

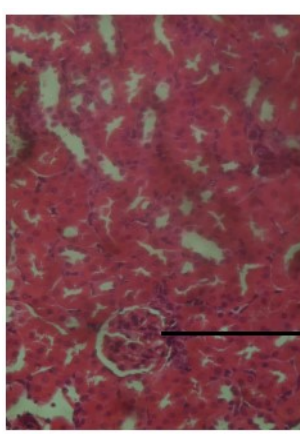

C: Group B

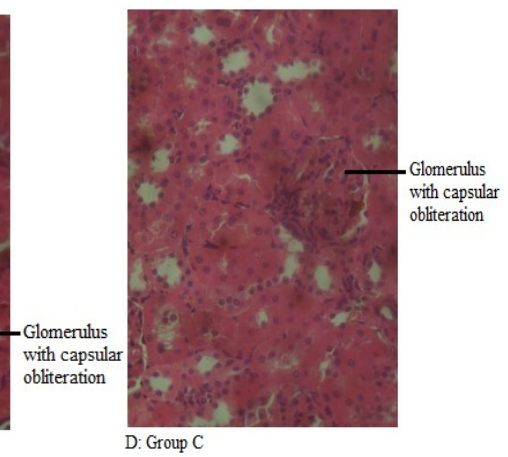

Int J Anat Res 2017, 5(4.3):4695-01. ISSN 2321-4287 
Biochemical assay: Serum urea and Creatinine levels in control and experimental animals were presented in tables 2 and 3. Tables 2-3 and figures 6-7 show the mean values of the biochemical parameters for animals in control as well as those treated with $40 \mathrm{mg} / \mathrm{kg}$ (group A), $80 \mathrm{mg} / \mathrm{kg}$ (group B) and $200 \mathrm{mg} / \mathrm{kg}$ (group C) of methanolic leaf extract of Baobab at the end of the first, second and third weeks and also at the end of reversal period.

Table 2: Effects of different doses of methanolic leaf extract of Baobab on urea level.

\begin{tabular}{|c|c|c|c|c|}
\hline \multirow{2}{*}{ WEEKS } & \multicolumn{4}{|c|}{ GROUPS } \\
\cline { 2 - 5 } & Control & Group A & Group B & Group C \\
\hline Week 1 & $3.30 \pm 0.10$ & $5.35 \pm 0.35$ & $5.70 \pm 0.30^{*}$ & $5.50 \pm 0.60^{*}$ \\
\hline Week 2 & $3.45 \pm 0.15$ & $5.90 \pm 0.30^{*}$ & $6.10 \pm 0.30^{*}$ & $6.40 \pm 0.40^{*}$ \\
\hline Week 3 & $3.40 \pm 0.10$ & $6.00 \pm 0.80^{*}$ & $6.25 \pm 0.25^{*}$ & $6.75 \pm 0.15^{*}$ \\
\hline Week 7 & $3.30 \pm 0.30$ & $4.10 \pm 0.10$ & $4.00 \pm 0.05$ & $6.65 \pm 0.25^{*}$ \\
\hline
\end{tabular}

Values are given as mean \pm SEM for 10 rats in each group $(n=10)$ * indicate significant difference $(p<0.05)$ compared to control group. $P$ : statistical level of significance as determined by one-way ANOVA followed by Tukeys' posthoc test.

Fig. 6: Mean urea level at different weeks of administration.

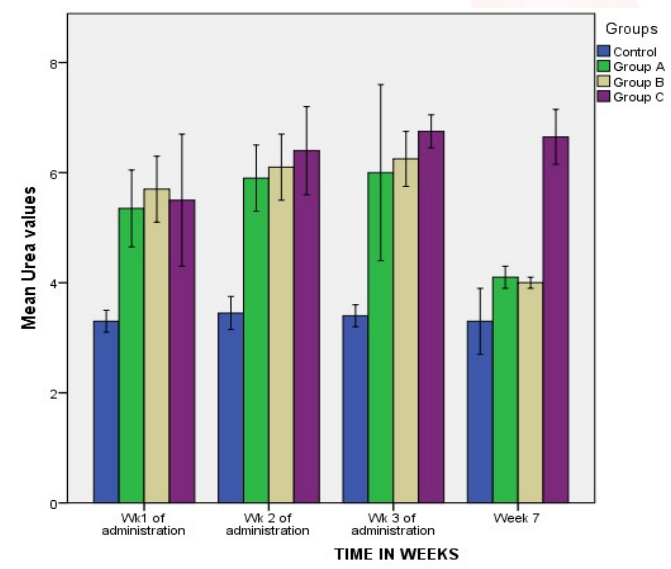

Table 3: Effects of different doses of methanolic leaf extract of Baobab on Creatinine level.

\begin{tabular}{|l|c|c|c|c|}
\hline \multirow{2}{*}{ WEEKS } & \multicolumn{4}{|c|}{ GROUPS } \\
\cline { 2 - 5 } & Control & Group A & Group B & Group C \\
\hline Week 1 & $83.5 \pm 0.20$ & $225.00 \pm 5.00^{*}$ & $253.00 \pm 5.00^{*}$ & $290.00 \pm 8.00^{*}$ \\
\hline Week 2 & $85.50 \pm 0.10$ & $263.00 \pm 3.00^{*}$ & $269.00 \pm 1.00^{*}$ & $357.00 \pm 6.00^{*}$ \\
\hline Week 3 & $83.50 \pm 0.40$ & $264.00 \pm 4.00^{*}$ & $277.00 \pm 8.00^{*}$ & $427.50 \pm 0.50^{*}$ \\
\hline Week 7 & $86.50 \pm 0.60$ & $125.00 \pm 1.00^{*}$ & $106.00 \pm 6.00^{*}$ & $424.50 \pm 1.40^{*}$ \\
\hline
\end{tabular}

Values are given as mean \pm SEM for ten rats in each group.* indicate significant difference $(p<0.05)$ compared to control group. $P$ : statistical level of significance as determined by oneway ANOVA followed by Turkeys' post-hoc test.
Fig. 7: Mean creatinine level at different weeks of administration.

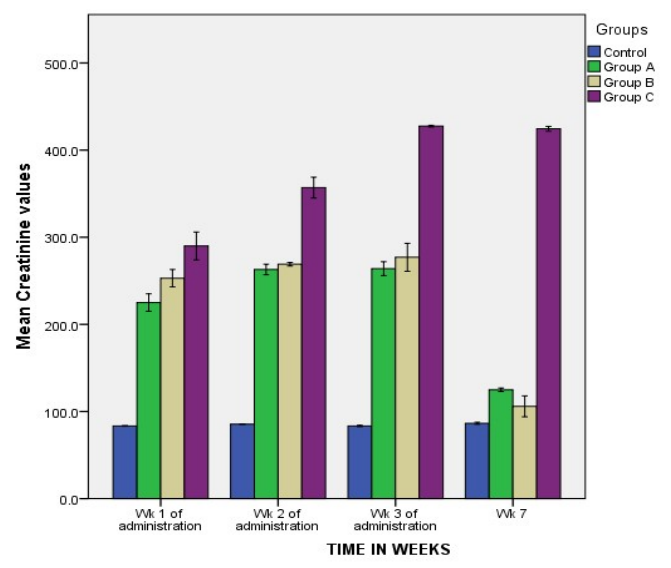

Urea: Table 2 contain the mean urea level in rats treated with different doses of the extract compared with the control group at the end of first, second and third weeks of administration. It also contain the mean urea values at the end of the wash-out period. At the end of week one, experimental groups (A-C) and control group (D) had mean urea values of $5.35 \pm 0.35,5.70 \pm 0.30$ $5.50 \pm 0.60$ and $3.30 \pm 0.10$ respectively. Statistically, the mean urea level of animals in groups $B$ and $C$ significantly increased $(p<0.05)$ compared to the control group (D). At the end of week two, the mean urea level for experimental groups (A-C) and control group (D) were $5.90 \pm 0.30,6.10 \pm 0.30,6.40 \pm 0.40$ and $3.45 \pm 0.15$, respectively. The result showed a significant increase $(p<0.05)$ in the mean urea level in experimental groups $(A-C)$ compared to the control group (D). Similarly, the mean urea level for experimental groups $(A-C)$ increased significantly $(p<0.05)$ at the end of the third week. When these values at the end of both week three and reversal period were compared, it was observed that mean urea values decreased appreciably in groups $A$ and $B$ animals but slightly in group $C$. The mean values at the end of wash-out period for experimental groups (A-C) as well as the control group (D) were $4.10 \pm 0.10,4.00 \pm 0.05,6.65 \pm 0.25$ and $3.30 \pm 0.30$ respectively. Even though these values increased progressively from groups $A$ to $C$ animals, only the value in group $C$ increased significantly $(p<0.05)$ when compared to that in the control group.

Creatinine: The mean creatinine level at the end of week one in the control group, groups $A, B$, and $C$ were $83.50 \pm 0.20,225.50 \pm 5.00$, 
$253.00 \pm 5.00$ and $290.50 \pm 8.00$ respectively. The mean creatinine level was statistically higher $(p<0.05)$ in groups $A, B$ and $C$ compared to the control group. Similarly, there was a significant elevation $(p<0.05)$ in mean creatinine values in groups $A, B$ and $C$ at the end of week two (table 3 ). Results at the end of the third week of administration showed similar trend to that in the second week (table 3 ) such that groups A, B and $C$ with mean creatinine value of $264 \pm 4.00$, $277.50 \pm 8.00$, and $427.50 \pm 0.50$ respectively showed a significant increase $(p<0.05)$ in plasma creatinine value when compared to control (83.50 \pm 0.50$)$. At the end of the reversal (washout) period, the mean creatinine levels in groups A (245.00 \pm 1.00$)$ and $B(106.00 \pm 0.00)$ were significantly elevated $(p<0.01)$ compared to the control group with a value of $86.50 \pm 2.50$. When these values at the end of both week three and reversal period were compared, it was observed that mean creatinine values decreased appreciably in groups $A$ and $B$ animals but slightly in group $C$. Even though these values depreciated at the end of both weeks, there was still a significant increase in serum creatinine value in all the experimental groups compared to the control group at the end of the reversal period.

\section{DISCUSSION}

In this present study, there was a progressive increase in mean body weight in both experimental and control groups from the acclimatization to the end of the wash-out period. This suggests that the extract did not significantly interfere with metabolic processes across the experimental groups. The animals continued to experience progressive growth which is one of the characteristics of living things. These observations are similar to a previous study [16], in which, it was reported that, the leaf extract of Baobab had no effect on body weight.

Histopathologic findings from this study revealed that, varying doses of the leaf extract, had mild to severe changes on the kidney. The progressive histopathologic distortion of the kidney as was observed from weeks one to three in group A $(40 \mathrm{mg} / \mathrm{kg})$, reverted to normal at the end of wash-out period. This trend demonstrated time-dependent reversible effects. Distortions in groups B $(80 \mathrm{mg} / \mathrm{kg})$ and C $(200 \mathrm{mg} / \mathrm{kg})$ seen during the period of extract administration (weeks 1-3) waned following wash-out period in group $B$, however it remained in group $C$. This clearly revealed an irreversible nephrotoxic effect in group $C$ (high dose). The nephrotoxic effect of the extract could be attributed to its pro-inflammatory effect[17] as well as by the theory of target organ toxicity[18]. The nephrotoxic effect of the extract could also be attributed to the presence of alkaloids. ${ }^{19}$ It was also suggested that presence of tannins also known as an anti-oxidant could at high dose be pro-oxidant hence increasing lipid peroxidation $[20,21]$.

Two important biomarkers used to investigate nephrotoxicity are plasma urea and creatinine. The progressive elevation of mean plasma urea and creatinine across the groups at the end of the first to third weeks of administration may be due to a progressive renal damage. Accumulation of both urea and creatinine in the plasma has been linked to inability of the kidney to effectively excrete these biomarkers due to renal damage $[23,23]$.These biomarkers which were elevated in all the experimental groups throughout a period of three weeks, corroborates with the histopathologic distortions observed in this study. This study also affirms a previous finding in which the leaf extract of Baobab exhibited a lowering effect on the concentration of serum albumin[24].

Several researches have proved that, low serum albumin level, was associated with renal inflammation and dysfunction hence a predictor of kidney function decline.[25,26, 27]. A decline in serum urea and creatinine concentrations, in groups $A$ and $B$ at the end of the wash-out period, may be attributed to regeneration of the distorted renal tissue and this is in agreement with the histologic findings in figure 5. Improvement in the histopathogic distortion of the kidney was demonstrated, when the findings at the end of the wash-out period were compared to the end of week three. Conversely, the slight decline in serum urea and creatinine values in experimental group $C$ at the end of the wash-out period compared to the end of week three suggests an irreversible renal distortion. The implication is that the nephrotoxic effect of the extract is irreversible at high 
dose as well as prolonged administration. This finding is similar to some previous studies which stated that the presence of tannins also known as an anti-oxidant could at high dose be pro-oxidant hence increasing lipid peroxidation of tissues [20, 21].

\section{CONCLUSION}

This study has shown that short to long-term consumption of Baobab leaf has no statistically significant effect on body weight. However, histo-pathologic changes were observed in the kidney, these changes were both dose-and timedependent. The effects were only reversible at low doses. Biochemical markers (Serum Urea and creatinine) corroborated these histopathologic findings. Thus, consumption of large quantities of Baobab leaf at regular and prolonged period should be discouraged as it has been shown to possess deleterious effects on the kidney.

\section{Conflicts of Interests: None}

\section{REFERENCES}

[1]. Sugandha S, Varsha P, Shashi R. Medicinal uses of Adansonia digitata Linn: An endangered tree species. Journal of Pharmaceutical and Scientific Innovation.2013;2(3): $\quad 14-15$

[2]. Wickens GE. and Lowe P. The baobabs: pachycauls of Africa, Madagascar and Australia. Springer. UK: 2008.

[3]. Chadare FJ, Linnemann AR, Hounhouigan JD, Nout MJR, Van Boekel MAJS. Baobab food products: a review on their composition and nutritional value. Critical Reviews in Food Science and Nutrition. 2009;49, 254-274.

[4]. Adason M. Description dun arbre nouveau genre appele Baobab, observe au Senegal [in French].Hist.Acad. Roy. Sci (Paris).1771; 218-243.

[5]. Gebauer J, El-Siddig K, Ebert G. Baobab (Adansonia digitata L.): a review on a multipurpose tree with promising future in the Sudan. Gartenbauwis senschaft. 2002; 67:155- 160.

[6]. Sidibe M, Williams JT. Baobab (Adansonia digitata) Fruits for the Future, 4. International Centre for Under-utilized Crops, Southampton, UK. 2002. p. 100

[7]. Van Wyk BE, Gericke N. A Guide to useful plants of Southern Africa. Pretoria (South Africa): Briza publications; 2000

[8]. Brendler T, Gruenwald J, Jaenicke C. Herbal remedies. (CD-ROM), Stuttgart: Medpharm GmbH Scientific Publishers; 2003.

[9]. Watt JM, Breyer-Brandwijk MG. The medicinal and poisonous plants of Southern and Eastern Africa.2nd ed. Edinburgh: E and S. Livingstone; 1962.

[10]. El-Rawy EM, Gergis SM, Bazaid S, El-Mougy SA. The Immunostimulant effect of Adansonia digitata on the immune response of chicken vaccinated with avian cholera vaccine. Journal of Egyptian Veterinary Medical Association.1997;57:959-970.
[11]. Tapsoba H, Deschamps JP. Use of medicinal plants for the treatment of oral diseases in Burkina Faso. Journal of Ethnopharmacolog. 2006;104:68-78.

[12]. De Caluwe E, Halamova K, Van Damme P. Baobab (Adansonia digitata L.): a review of traditional uses, phytochemistry and pharmacology, USA: Oxford University Press. 2009:51-84.

[13]. Standring S. Gray's Anatomy: the Anatomical Basis of Clinical Practice (39th ed.). Churchill Livingstone. 2004: 1269-1274.

[14]. Disbrey BD, Rack JH. Histological Laboratory Methods. Edinburgh: Livingstone1974: 56-128.

[15]. Drury RAB, Wallington EA. Careton's Histological Technique, (4th ed.) London: Oxford University Press. 1967;120-123.

[16]. Oyetunji OA, Babatunde IR, Chia SL, Abraham OA, Bernard AF, Olugbenga E. Esemekiphoro WF. Ameliorative effects of Adansonia digitata leaf extract on carbon tetrachloride (CCL4) induced testicular toxicity in adult male wistar rats. Anatomy Journal of Africa. 2015;4(1):481-487.

[17]. Vimalanathan S, Hudson JB. Multiple inflammatory and antiviral activities in Adansonia digitata (Baobab) leaves, fruits and seeds. Journal of Medicinal Plants Research. 2009;3: 576-582.

[18]. Heywood R. Target Organ toxicity. Toxicology Letters. 1981;8(6):349-358.

[19]. Burkill HM. The useful plants of West Tropical Africa. Royal botanical Gardens;1994.

[20]. Taitzoglou A, Tsantarliotou M, Zervos I, Kouretas D, Kokolis N. Inhibition of human and bovine acrosomal enzymes by tannic acid in vitro. Journal of the Society for Reproduction and Fertility. 2001;121:131137.

[21]. Nworgu FC, Ekemezie AA, Ladele AO, Akinrolabu BM. Performance of broiler chickens served heat-treated fluted pumpkin leaves extract supplement. African Journal of Biotechnology. 2007; 6(6): 818-825.

[22]. Dollah MA, Parhizkar S, Izwan M. Effects of Nigella sativa on the kidney function in rats. Avicenna Journal of Phytomedicine.2012; 3(2): 152-158.

[23]. Abdulmumin Y, Matazu KI, Wudil AM, Alhassan AJ, Imam AA. Nephrocurative effects of Boswellia papyrifera (DEL) against acetaminophen-induced kidney damage in rats. Ife Journal of Science. 2014;16(3): 395-403.

[24]. Geidam MA, Oyesola SA, Kokori M. Effects of methanolic leaf extract of Adansonia digitata (Linn) on serum electrolyte levels in normal and alcohol fed rats.Pakistan Journal of Biological Sciences. 2003;7(8):1404-1406.

[25]. Duerksen DR, Papineau N. Electrolyte abnormalities in patients with chronic renal failure receiving parenteral nutrition. Journal of Parenteral and Enteral Nutrition. 1998;22(2): 102-104.

[26]. Sort P, Navasa M, Arroyo, V, Aldeguer X, Planas R, Ruiz-del-Arbol L, Castells L, Vagas V, Soriano G, Guevara M, Gines P, Rodes J. Effect of intravenous albumin on renal impairment and mortality in patients with cirrhosis and spontaneous bacterial peritonitis. New England Journal of Medicine. 1999;341(6): 403-409.

[27]. Wiedermann CJ, Joannidis M. Nephroprotective potential of human albumin infusion: a narrative review. Gastroenterology research and practice; 2015. 